\title{
A thermo-mechanical model for SFRC beams or slabs at elevated temperatures
}

\author{
Peter Heek $\cdot$ Jasmin Tkocz $\cdot$ Peter Mark
}

Received: 23 January 2018/ Accepted: 16 June 2018/Published online: 21 June 2018

(C) The Author(s) 2019, corrected publication April 2019

\begin{abstract}
The bearing capacity of steel fibre reinforced concrete (SFRC) at elevated temperatures is the subject of significant ongoing research, as the effect of steel fibres on concrete performance at higher temperatures is poorly understood. On one hand, steel fibres increase the average thermal conductivity of the concrete cross section and lead to greater heating within a concrete structural member during fire exposure, and on the other, fibres reduce crack widths and prevent excessive spalling. The former effect negatively impacts SFRC performance at high temperature, whereas the latter effect protects the inner structure from direct fire exposure. Additionally, the decreasing strength of steel at higher temperatures can result in the sudden failure of fibre or traditionally reinforced concrete. Within this contribution, a coupled thermo-mechanical model is developed in order to investigate the influence of steel fibres on the
\end{abstract}

The original version of this article was revised due to a retrospective Open Access order.

P. Heek · J. Tkocz $(\bowtie) \cdot$ P. Mark

Institute of Concrete Structures, Ruhr-University

Bochum, Universitätsstraße 150, 44780 Bochum,

Germany

e-mail: jasmin.tkocz@rub.de

P. Heek

e-mail: peter.heek@rub.de

P. Mark

e-mail: peter.mark@rub.de thermal loading of concrete. The effect of fibres on heat transmission within concrete, the length of time for which concrete can sustain thermal loads, and on the bending stiffness of reinforced concrete beams or slabs is investigated. The heat transfer process is modelled using Fourier's partial differential equation of transient heat conduction. A modified plastic hinge model and moment-curvature relations are used to describe stress-dependent deformations. Thus, two alternative approaches are used to adequately track the localisation of damage for single cracks and for distributed and multiple cracking. Thermo-mechanical coupling is achieved by means of temperaturedependent stress-strain relations. These are derived for SFRC based on experimental data from the literature. Experiments are performed in which concrete slabs reinforced with variable amounts of fibres and rebar are exposed to combined thermal and mechanical loadings. The results of these experiments are used to validate the proposed model. The measured and predicted results agree well and indicate that steel fibres have a positive effect on the fire resistance of structures, assuming additional rebar is provided to prevent crack localisation. Additionally, it is shown that temperature fields within concrete remain almost unaffected by variations in fibre content.

Keywords Thermo-mechanical modelling - Heat transfer - Thermal effects - Fire resistance duration . Moment-curvature relation - Plastic hinge model . Fibre reinforced concrete $\cdot$ Large-scale tests 


\section{List of symbols}

$a$

A

$c_{\text {nom }}$

$c_{\mathrm{p}}$

$d_{\mathrm{f}}$

e, E

$f_{\mathrm{c}}, f_{\mathrm{t}}, f_{1}^{\mathrm{f}}, f_{2}^{\mathrm{f}}$

F

$g, i, j, k, n, r$

I

$k_{\mathrm{t}}^{\mathrm{f}}$

$l, l_{\mathrm{ch}}, l_{\mathrm{f}}$

$m, M, \bar{M}$

$q, Q$

$R$

$s_{i}, l_{i, k}$

$S$

SLS

$t, T$

ULS

$V_{\mathrm{f}}$

$w$

$\boldsymbol{x}, x, y, z$

$\alpha_{\mathrm{K}}, \alpha_{\mathrm{T}}$

$\delta, \delta^{\text {th }}, \delta^{\sigma}$

$\varepsilon, \varepsilon_{\mathrm{c}, \mathrm{top}}, \varepsilon_{\mathrm{c}, \mathrm{bot}}$,

$\varepsilon_{\mathrm{s} 1}$

$\varepsilon_{\mathrm{f}}, \varepsilon_{\mathrm{m}}$

$\theta, \theta_{0}, \theta_{\mathrm{r}}$
Thermal diffusivity

Cross-sectional area

Concrete cover

Specific heat capacity

Fibre diameter

Spacing of loading, modulus of elasticity

Strength (compressive concrete strength, tensile concrete strength, and post-cracking tensile strengths of SFRC corresponding to predefined strains $\varepsilon_{1}$ and $\varepsilon_{2}$, respectively)

Force

Counter variables

Moment of inertia

Ratio of SFRC's post-cracking tensile strength at elevated temperatures to that at normal temperature

Length, characteristic length, fibre length

Mass, bending moment, virtual bending moment

Heat flux density, heat flow volume

Fire resistance duration in minutes

Element sizes (element length in

direction of the heat flow, contact

length between two adjacent elements

$i$ and $k$ perpendicular to the heat flow)

Width of a plastic hinge

Serviceability limit state

Time, absolute temperature

Ultimate limit state

Fibre volume content

Crack width

Vector of a spatial location, spatial coordinates (Cartesian)

Fictive heat-transfer coefficient, thermal expansion coefficient

Deflections (overall, thermic and stress-dependent)

Strains (overall, concrete strains at the top or bottom of a section, rebar strain)

Emission coefficients (fumes and solid)

Radiation temperature (overall, initial), rotation angle $\vartheta, \vartheta_{0}, \vartheta_{\mathrm{m}}, \quad$ Temperature (basic, initial, average,

$\Delta \vartheta, \vartheta_{\text {ID }} \quad$ difference, equivalent)

$\kappa \quad$ Curvature

$\lambda \quad$ Thermal conductivity

$\rho \quad$ Density

$\sigma, \sigma_{\mathrm{c}}, \sigma_{\mathrm{t}}, \sigma_{\mathrm{s} 1} \quad$ Stress (general, concrete in compression and tension, in longitudinal rebar)

$\sigma_{\mathrm{SB}} \quad$ Stefan-Boltzmann constant

$\varphi, \varphi_{\mathrm{el}}, \varphi_{\mathrm{pl}} \quad$ Rotation angle (overall, elastic and plastic portions)

\section{Introduction}

Steel fibre reinforced concrete (SFRC) is widely used in civil engineering as it considerably enhances the reliability of reinforced concrete structures. Although many different fibre types are available, mechanically anchored steel macro fibres have been proven to be especially suitable for retarding crack growth in concrete after crack formation. The governing parameters that influence the post-cracking tensile strength of SFRC are fibre type, dosage, orientation and the fibre-concrete bond conditions [1, 2]. At subcritical fibre contents, SFRC exhibits a softening material response after cracking. Low-fibre-content reinforcement is therefore often used in conjunction with traditional rebar to ensure the structural integrity of reinforced concrete members on a cross sectional level. In contrast, supercritical fibre contents induce material stiffening after concrete cracking.

In common ultimate limit state (ULS) design [3], the necessary rebar reinforcement ratios can be significantly reduced if steel fibres are also included as a component of the reinforcement scheme $[4,5]$. However, in the case of fire resistant design, the postcracking tensile strength of SFRC is not taken into account by any current or pre-normative standard [6]. It is conservatively assumed that only rebar carries tensile loads at elevated temperatures. This leads to difficulties in determining the necessary residual bearing capacity of a reinforced concrete member [7], as the contribution of the fibres to the strength of the remaining cross-section after loading is neglected. Significant strength reserves may therefore be overlooked in the standard design process. The thermal 
conductivity and the temperature-variant stress-strain response of SFRC are therefore an object of interest in current SFRC research [8-16].

The impact of fibres on heat transmission is a controversial subject among experts. Various sources report that the presence of steel fibres accelerates heating rates within concrete [17], whereas other sources claim that fibres retard the heating process [18]. The enhanced conductivity of steel compared to that of concrete may result in varying temperature distributions within the composite material, which may lead to local damage within a given cross section. Conversely, if cracks develop within a concrete member during heating, steel fibres prevent excessive concrete spalling and thus protect the inner structure from direct damage under sustained fire exposure. This protective effect is, however, only present as long as the heated fibres are able to sufficiently transfer tensile forces across a crack. If the fibres themselves are heated to such an extent that their tensile strength becomes negligible, the fibres cannot fulfil their intended purpose.

In order to predict SFRC behaviour under thermal loading, it is essential to properly analyse the interaction between the thermal and mechanical behaviour of the material. Within this contribution, a coupled thermo-mechanical model for SFRC is presented. The model is used to investigate both the heat propagation as a function of the fibres' volume contents and the overall load-bearing capacity of SFRC members subjected to bending while exposed to fire. Effects of local concrete spalling or time-dependent behaviour, such as creep or viscosity changes, are not considered explicitly. Large-scale fire tests conducted on concrete slabs reinforced with both steel fibres and traditional reinforcement are used to verify the results. The tested slabs are heated according to a uniform temperature time curve according to Eurocode 1-1-2 [19].

\section{Modelling the thermo-mechanical behaviour}

The weakly coupled model is derived in three steps. At first, the equation of heat transfer in solid bodies is presented. Second, the bending behaviour of SFRC elements with or without rebar under mechanical loadings is introduced and third, the two strain fields are coupled by overlapping portions and introducing temperature-dependent stress-strain laws. Since stress-states are assumed not to influence heat transmission, the heat flux is derived a priori. Throughout, damage induced material loss due to spalling is neglected so that the initial geometry is preserved.

\subsection{Heat transmission}

The model is based upon the principles of continuous composite body heat transmission. For the sake of simplicity, fire exposure or down-cooling to ambient conditions are assumed to occur at the outer boundaries from convective and radiative portions only while inner heat sources are generally neglected.

The temperature field $\vartheta(\boldsymbol{x}, t)$ in the solid depends on the spatial location $\boldsymbol{x}$ and time $t$, which changes progressively due to temperature exposure and the corresponding temperature gradients entailing a heat flow in the gradient's direction. Considering heat balance in an incremental volume element Fourier's partial differential equation of transient heat transmission [20, 21] yields:

$\frac{\partial \vartheta(\boldsymbol{x}, t)}{\partial t}-a \nabla^{2} \vartheta(\boldsymbol{x}, t)=0$.

The solid is assumed to be homogeneous and isotropic, which also holds true for any arbitrary, infinitesimal volume therein. Consequently, the thermal diffusivity a simplifies to a scalar, denoted by $a=\lambda /\left(\rho c_{\mathrm{p}}\right)$, the ratio of the thermal conductivity $\lambda$ to the product of material density $\rho$ and specific heat capacity $c_{\mathrm{p}}$.

The heat flow volume $Q[\mathrm{~J}]$ of a solid is computed from its mass $m$, its specific heat capacity and temperature $T[\mathrm{~K}]$ relative to absolute zero at $0 \mathrm{~K}=-273.15{ }^{\circ} \mathrm{C}$.

$Q=m c_{\mathrm{p}} T$

Two volume fractions with a contact area $A$ exchange heat flow volume increments $\mathrm{d} Q$ per time increment $\mathrm{d} t$, which is described by the heat flux density $\dot{q}$.

$\dot{q}=\frac{\mathrm{dQ}}{A \mathrm{~d} t}=-\lambda \nabla \vartheta(\boldsymbol{x}, t)$

Since heat flux and the field of temperature gradients are proportionally coupled, Cartesian components can be derived in the three spatial directions $x$, $y$ and $z$. 
$\dot{q}_{x}=-\lambda \frac{\partial \vartheta}{\partial x}, \quad \dot{q}_{y}=-\lambda \frac{\partial \vartheta}{\partial y}, \quad \dot{q}_{z}=-\lambda \frac{\partial \vartheta}{\partial z}$.

Separation into $x, y$ and $z$ components benefits the numerical solution of heat transfer by discretising space and time domains [22, 23] using consistent rectangular volume elements and time steps $\Delta t$, respectively. Figure 1 illustrates such a spatial discretisation of a reinforced beam with boundary contact elements simulating ambient or fire conditions. The arrangement is chosen to effectively derive transient temperature propagation in spreadsheet environments [24-27]. Material elements are idealised by specific cells in the spreadsheet surrounded by others to model boundary conditions of convection and radiation.

Starting with an initial temperature field $\vartheta(\boldsymbol{x}, t)$ at a time $t$, the current distribution at the end of a time step $t+\Delta t$ is obtained by explicit time integration. Temperatures are assumed to remain stepwise constant in $\Delta t$ while the heat flow changes. For convenience derivations are restricted to two-dimensional cases in the remainder.

Cross-sections are discretised by rectangular elements. Each element $i$ is characterised by an associated area $A_{i}=x_{i} z_{i}$, its average temperature $\vartheta_{i}$ at a time $t$ and its thermal diffusivity $a_{i}$. Internal elements are surrounded by $g=4$ solid elements. By contrast,

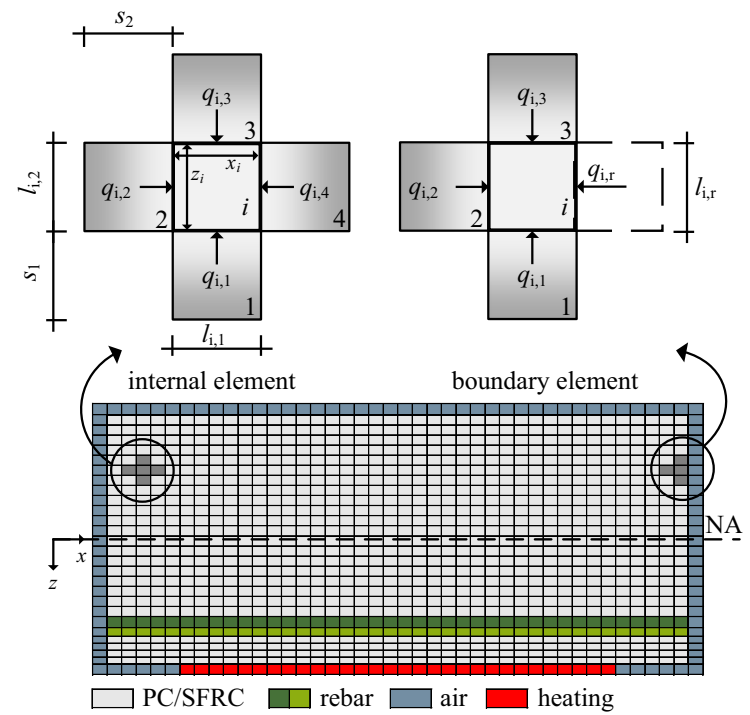

Fig. 1 Discretised solid body with boundary conditions (bottom) and heat flux in internal and boundary elements (top) boundary elements exhibit one or two free surfaces $(r)$ that reduce the number of the inner surfaces to $g=4-r$. An alteration of heat flow volume $\left(\Delta Q_{i} /\right.$ $\Delta t$ ) results from the sum of up to four densities $\dot{q}_{i}$ along the inner or boundary contact lengths $l_{i, j}$ and $l_{i, r}$.

$\frac{\Delta Q_{i}}{\Delta t}=\sum_{j=1}^{g} \dot{q}_{i, j} l_{i, j}+\sum_{r=1}^{4-g} \dot{q}_{i, r} l_{i, r}$

Thereby, the directed heat flow density between two differently heated internal elements $i$ and $k$ depends on the element lengths $s_{i}, s_{k}$, the thermal conductivities $\lambda_{i}, \lambda_{k}$ and the temperature difference between $\vartheta_{i}$ and $\vartheta_{k}$.

$\dot{q}_{i, k}=\frac{2 \lambda_{i} \lambda_{k}}{\lambda_{k} s_{i}+\lambda_{i} s_{k}}\left(\vartheta_{k}-\vartheta_{i}\right)$

Boundary conditions, i.e. heat sources or cooling at the surfaces, are treated similarly. For this purpose the corresponding component is replaced by a fictitious transfer quantity from or to the outside of the body.

$\dot{q}_{i, r}=\frac{2 \lambda_{i} \alpha_{\mathrm{K}, i}}{\alpha_{\mathrm{K}, i} s_{i}+2 \lambda_{i}}\left(\vartheta_{\mathrm{ID}, i}-\vartheta_{i}\right)$

Convective and radiative portions are modelled by an equivalent temperature $\vartheta_{\text {ID }}$ depending on a fictitious heat-transfer coefficient $\alpha_{K}$ [28] and the surface temperature $\vartheta_{0}[22,29]$.

$\vartheta_{\mathrm{ID}}=\vartheta_{0}+\frac{1}{\alpha_{\mathrm{K}}} \dot{q}_{0}=\vartheta_{0}+\frac{1}{\alpha_{\mathrm{K}}}\left[\alpha_{\mathrm{K}}\left(\vartheta_{\mathrm{A}}-\vartheta_{0}\right)+\dot{q}_{\mathrm{rad}}\right]$

In case of fire exposure, the radiative heat flow $\dot{q}_{\text {rad }}$ becomes a function of the grey body emission coefficients of the solid $\varepsilon_{\mathrm{m}}$ and the surrounding fumes $\varepsilon_{\mathrm{f}}[21] . \sigma_{\mathrm{SB}}$ denotes the Boltzmann constant.

$\dot{q}_{\mathrm{rad}}=\varepsilon_{\mathrm{f}} \varepsilon_{\mathrm{m}} \sigma_{\mathrm{SB}}\left[\left(\vartheta_{\mathrm{A}}+273.15\right)^{4}-\left(\vartheta_{0}+273.15\right)^{4}\right]$

The radiation temperature $\vartheta_{\mathrm{A}}$ and the surface temperature $\vartheta_{0}$ are both related to absolute zero. For the sake of simplicity, $\vartheta_{\mathrm{A}}$ can be set to the discharge temperature of the fumes, $\vartheta_{\mathrm{A}}=\theta$ [28] and $\vartheta_{0}$ to the corresponding element's one $\vartheta_{0}=\vartheta_{i}$. Hence, the temperature field at the end of a time step reads:

$\vartheta_{i}^{t+\Delta t}=\vartheta_{i}^{t}+\frac{1}{c_{\mathrm{p}, \mathrm{i}}(\vartheta) \rho_{i}(\vartheta) x_{i} z_{i}} \frac{\Delta Q_{i}}{\Delta t} \Delta t$. 
To ensure numerical stability the time step size $\Delta t$ $[22,23]$ has to be limited. For two-dimensional cases it depends on thermal parameters $\left(c_{\mathrm{p}}, \rho, \lambda\right)$ and element sizes $\left(x_{i}, z_{i}\right)$ :

$\Delta t \leq \frac{c_{\mathrm{p}, i} \rho_{i}}{2 \lambda_{i}} \frac{x_{i}^{2} z_{i}^{2}}{x_{i}^{2}+z_{i}^{2}}$

To reduce the computational demand the check might be restricted to the smallest element of a discretisation.

\subsection{SFRC beams or slabs under mechanical loading}

Elevated temperatures considerably affect the mechanical material response of plain concrete (PC), SFRC and steel rebar. Stresses are a function of strains and both depend on temperature. Introducing a separation of strains into thermal (superscript th) and purely stress-dependent (superscript $\sigma$ ) portions according to [7] gives:

$\varepsilon=\varepsilon^{\text {th }}+\varepsilon^{\sigma}=\alpha_{\mathrm{T}} \Delta \vartheta+\varepsilon^{\sigma}$.

Thus, mechanical and thermal analyses can be conducted independently.

A softening material effect due to elevated temperatures can be considered in mechanical analyses only. In this case $\varepsilon^{\text {th }}$ purely arises from temperature differences $\Delta \vartheta$ and the coefficients of thermal expansion $\alpha_{\mathrm{T}}(\vartheta)$.

Mechanical modelling considers bending moments $M$ and axial forces $N$ only, shear deformations are neglected. On cross-sectional level strains are distributed linearly over the cross-section's height $h$. Moreover, the bond between concrete and rebar is assumed perfect and slip free. Uniaxial stress-strain laws describe the mechanical response of PC, SFRC and rebar which depend on the current temperature of the material and thus change with time. Applying equilibrium conditions for a two dimensional case yields:

$$
\begin{aligned}
& N=\iint_{A} \sigma \mathrm{d} A \tilde{=} \iint_{A} \sigma_{\mathrm{c}} \mathrm{d} A+\sum_{i=1}^{n} A_{\mathrm{si}} \sigma_{\mathrm{si}} \\
& M=\iint_{A} \sigma z \mathrm{~d} A \tilde{=} \iint_{A} \sigma_{\mathrm{c}} z \mathrm{~d} A+\sum_{i=1}^{n} A_{\mathrm{si}} z_{\mathrm{i}} \sigma_{\mathrm{si}}
\end{aligned}
$$

introducing stresses $\sigma_{\mathrm{c}}$ of PC or SFRC, the crosssectional area $A, n$ layers of reinforcement $A_{\mathrm{s}}$ with stresses $\sigma_{\mathrm{s}}$ and the vertical coordinate $z$. Figure 2 illustrates the situation for a standard beam with one reinforcement layer at the bottom. A nonlinear stressstrain law for SFRC is applied considering the beneficial effect of fibres in a smeared way by additional tensile bearing capacities.

For an iterative numerical solution of Eqs. $(13,14)$, the cross-sectional height is partitioned into equally spaced layers, corresponding to the discretisation of the thermal analysis to allow direct superposition of thermal and mechanical portions according to Eq. (12). The appropriate strain plane is derived using optimisation methods $[24,30]$ that robustly and efficiently solve the nonlinear equilibrium problem by minimisation of residuals between outer forces $N$ and $M$ and corresponding stress integrals [24].

To facilitate a transfer of the proposed calculation method to the longitudinal direction of beams or slabs it has to be distinguished between single (localised) and multiple cracking.

\subsubsection{Multiple cracking}

Bernoulli's theorem of thin and transversely rigid beams enables the derivation of temperature-variant curvatures $\kappa(\vartheta)$ which depend on the strains in equilibrium at the outermost fibres of a cross-section. These are generally located at the bottom $\varepsilon_{\mathrm{c}, \text { bot }}$ and at the top $\varepsilon_{\mathrm{c}, \text { top }}$ (Fig. 2) [31].

$\kappa(\vartheta)=\frac{\varepsilon_{\mathrm{c}, \mathrm{bot}}(\vartheta)-\varepsilon_{\mathrm{c}, \text { top }}(\vartheta)}{h}=\frac{M}{E_{\mathrm{c}} I(\vartheta)}$

Since both strains are induced by stresses, $\kappa$ reflects the ratio of bending moment $(M)$ to bending stiffness $\left(E_{\mathrm{c}} I\right)$ in non-cracked as well as in cracked states. Thus, an individual moment-curvature relation has to be derived for each cross-section being considered. The principle of virtual work

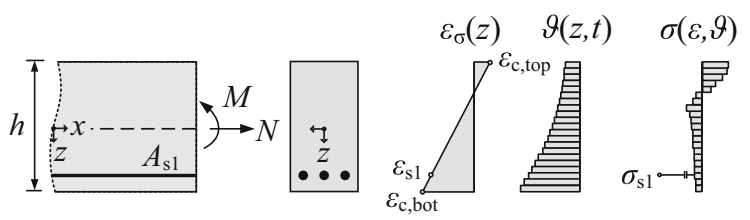

Fig. 2 Strain and stress distributions over the cross-section's height for a SFRC beam with one layer of rebar 
$\delta(x)=\int_{0}^{l} \kappa(x) \bar{M}(x) \mathrm{d} x$

and Simpson's rule are employed to numerically integrate the curvature $\kappa(x)$ and the virtual bending moment $\bar{M}(x)$ along $x$ resulting in the vertical deflections $\delta(x)$. Of course, a suited number of integration points along the length $l$ has to be provided to adequately cover stiffness reductions due to cracking. Furthermore, tension stiffening might be approximated by modified stress-strain relations of rebar [5].

\subsubsection{Localisation due to single cracking}

The softening post-cracking response of SFRC beams containing subcritical amounts of steel fibres but no additional rebar causes a localisation of deflections at single cracks $[2,3,32]$. Within the fracture process zone a discontinuity, often denoted a plastic hinge, forms that governs the beam's deflections by its rotation. Rotation depends on the strain distribution in the region that develops nonlinearly over the width of the hinge. To transfer localisation to a quasi-continuous approach, Strack [33] developed a plastic hinge model. It is based on average strains of the tensile and compressive fibres in the discontinuity region, while equilibrium is checked at the cracked cross-section only, Fig. 3. In this regard, uniaxial material functions by means of stress-crack-width relations $\sigma(w)$ according to $[32,33]$ are transferred to stress-strain ones $\sigma(\varepsilon)$ and vice versa introducing a characteristic length $l_{\mathrm{ch}}$ according to the notion of a crack band [34]. Assuming linear elastic stress-strain behaviour in the noncracked state, the post cracking strains consist of elastic $\left(\varepsilon_{\mathrm{el}}\right)$ and plastic $\left(\varepsilon_{\mathrm{pl}}\right)$ portions:

$\varepsilon=\varepsilon_{\mathrm{el}}+\varepsilon_{\mathrm{pl}}=\frac{\sigma}{E_{\mathrm{c}}}+\frac{w}{l_{\mathrm{ch}}}$.

In case of common macro fibres the characteristic length $l_{\text {ch }}$ corresponds to about twice the fibre's length and thus to an almost constant value. Subsequently, $l_{\mathrm{ch}}$ is set equal to $140 \mathrm{~mm}$ based on [2]. This value approximately refers to fibre lengths of $50-80 \mathrm{~mm}$ and-at least for thin structures in bending-resembles $l_{\text {ch }} \approx h$, as advised in [3].

Strack's plastic hinge model was originally proposed for SFRC subjected to short term loadings at normal temperatures [33], but allows for generalisations in case of fatigue [35] or elevated temperatures. Elevated temperature requires customisation of the material behaviour only. Moreover, the calculation procedure is more reliable when load instead of deformation controlled. While the geometry of the beam, its loading pattern and temperature-dependent material behaviour are prescribed for each discrete time step, the strains at the border of the hinge are iteratively computed. Subsequently, the basic model is
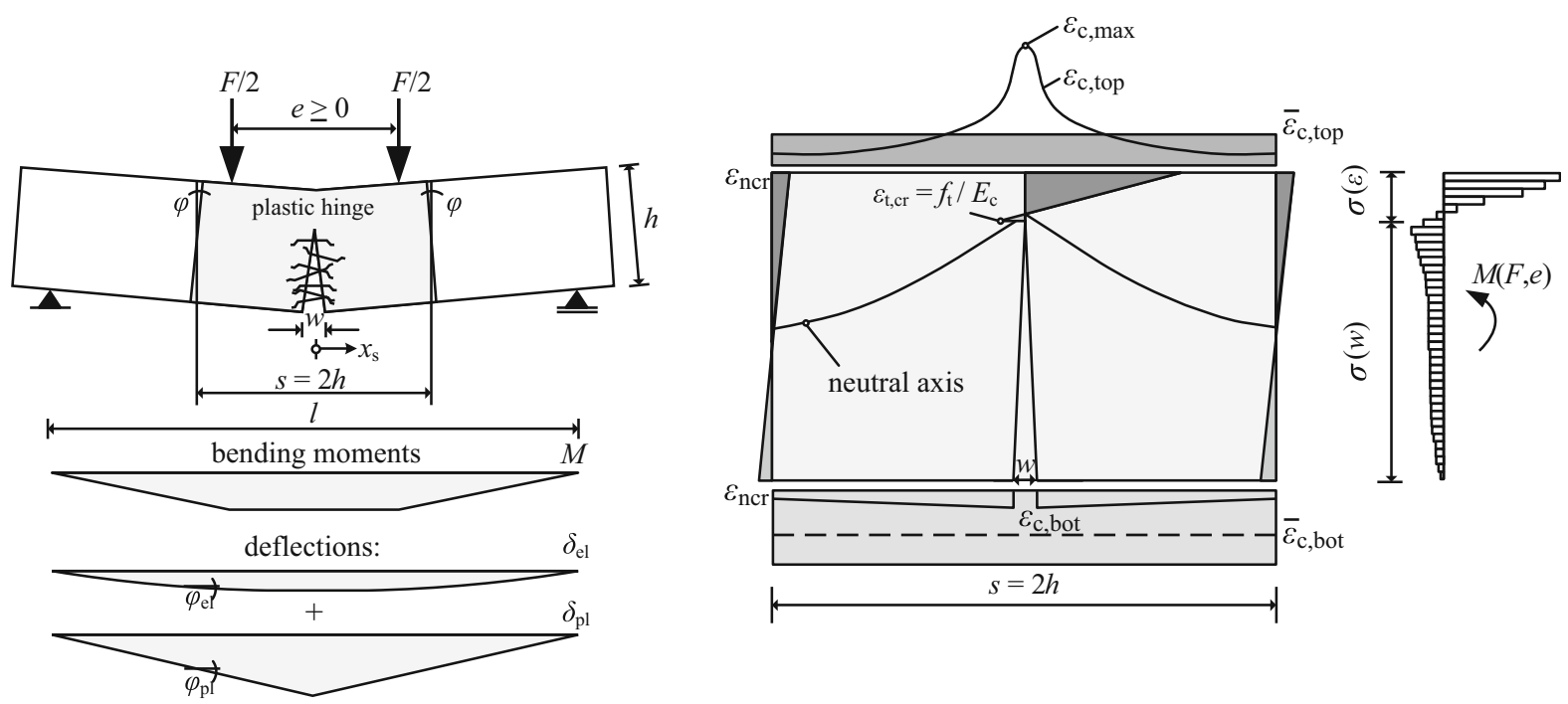

Fig. 3 Basic parameters of Strack's plastic hinge model [33], left: structural system as well as geometry and deflection characteristics; right: strain and stress distributions

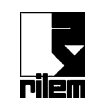


briefly summarised in its key aspects respecting temperature dependencies and axial forces for the sake of simplicity.

Presuming a stress distribution at $45^{\circ}$ from the compressed to the tensile edge, the longitudinal extent of the plastic hinge equals about twice the crosssection's height, $s=2 h$ [33]. In non-cracked regions (subscript ncr), strains $\varepsilon_{\text {ncr }}$ are obtained based on linear elastic theory.

$\varepsilon_{\mathrm{ncr}}=\frac{M}{W_{\mathrm{ncr}} E_{\mathrm{c}}}$

Here, $W_{\text {ncr }}$ denotes the sectional bending resistance and $M$ the bending moment, which can be induced by three $(e=0)$ or four-point $(e>0)$ bending from the force $F$. Average tensile $\left(\bar{\varepsilon}_{\mathrm{c}, \text { bot }}\right)$ and compressive $\left(\bar{\varepsilon}_{\mathrm{c}, \text { top }}\right)$ strains at the edges describe the hinge's overall deformation. They depend on the deflections in equilibrium and result from the tensile and the compressive zone of the cracked cross-section, respectively. Within the tensile zone an artificial strain $\bar{\varepsilon}_{\mathrm{c}, \text { bot }}=\bar{\varepsilon}_{\mathrm{el}}+\bar{\varepsilon}_{\mathrm{w}}$ is introduced by summing up average elastic strains $\left(\bar{\varepsilon}_{\mathrm{el}}\right)$ and the maximum crack width $w$ smeared over the hinge's width [33]. Thereby, a linear crack opening over the cross-section's height is assumed.

$$
\begin{aligned}
\bar{\varepsilon}_{\mathrm{el}}= & \frac{1}{2 h} \int_{-h}^{h} \varepsilon_{\mathrm{c}, \mathrm{bot}} \mathrm{d} x_{\mathrm{s}}=\frac{1}{2 h}\left[\varepsilon_{t, \max }(h+e / 2)\right. \\
& \left.+\varepsilon_{\mathrm{ncr}}(h-e / 2)\right] \\
\varepsilon_{t, \max } & =\frac{M}{W_{\mathrm{ncr}} E_{\mathrm{c}}} \leq \varepsilon_{t, \mathrm{cr}}=\frac{f_{\mathrm{t}}}{E_{\mathrm{c}}} \\
\bar{\varepsilon}_{\mathrm{W}} & =\frac{w}{s}
\end{aligned}
$$

Cracking occurs if the induced strains exceed $\varepsilon_{t, \mathrm{cr}}$, which equals the ratio of concrete's tensile strength $f_{\mathrm{t}}$ to its Young's modulus $E_{\mathrm{c}}$. The average compressive strains follow iteratively considering the height of the compressive zone $x_{\mathrm{c}}=\xi h$ and exhibit a distinct nonlinear course as indicated by $\varepsilon_{\mathrm{c}, \text { top }}$ [33] in Fig. 3 .

$$
\begin{aligned}
\bar{\varepsilon}_{\mathrm{c}, \text { top }}= & \frac{1}{2 h} \int_{-h}^{h} \varepsilon_{\mathrm{c}, \text { top }} \mathrm{d} x_{\mathrm{s}}=\varepsilon_{\mathrm{ncr}}-\left(\varepsilon_{\mathrm{ncr}}\right. \\
& \left.-\varepsilon_{\mathrm{c}, \max }\right)\left[\arctan (1 / \eta)\left(\eta^{3}+\eta\right)-\eta^{2}\right]
\end{aligned}
$$

with: $\quad \varepsilon_{\mathrm{c}, \max }=\varepsilon_{\mathrm{ncr}}-\frac{\varepsilon_{\mathrm{ncr}}-\bar{\varepsilon}_{\mathrm{c}, \text { top }}}{\arctan (1 / \eta)\left(\eta^{3}+\eta\right)-\eta^{2}} \quad$ and $\eta=2 \xi=\frac{\left|\bar{\varepsilon}_{\mathrm{c} \text { top }}\right|}{\overline{\bar{c}}_{\mathrm{c}, \mathrm{bot}}}$.

The hinge's overall rotation $\theta_{\mathrm{r}}$ consists of elastic (subscript el) and plastic (subscript pl) portions arising from the average strains.

$\theta_{\mathrm{r}}=\theta_{\mathrm{r}, \mathrm{el}}+\theta_{\mathrm{r}, \mathrm{pl}}=2 \phi=2\left(\bar{\varepsilon}_{\mathrm{c}, \text { bot }}-\bar{\varepsilon}_{\mathrm{c}, \text { top }}\right)$

The same characteristic applies to the corresponding deflections $\delta$ that are superimposed analogously.

$\delta=\delta_{\mathrm{el}}+\delta_{\mathrm{pl}}$

with

$$
\begin{gathered}
\delta_{\mathrm{el}}=\frac{F \Lambda(l-e)}{48 E_{\mathrm{c}} I}\left[3 l^{2}-4\left(\frac{l-e}{2}\right)^{2}\right] ; \\
\Lambda= \begin{cases}1, & e=0 \\
2, & e>0\end{cases}
\end{gathered}
$$

and

$$
\begin{aligned}
\delta_{\mathrm{pl}} & =\theta_{\mathrm{r}, \mathrm{pl}} \frac{l}{4}=2\left(\bar{\varepsilon}_{\mathrm{c}, \text { bot }}-\bar{\varepsilon}_{\mathrm{c}, \text { top }}-2\left|\bar{\varepsilon}_{\mathrm{el}}\right|\right) \frac{l}{4} \\
& =\frac{w}{(1-\xi) h} \frac{l}{4} .
\end{aligned}
$$

Therein, $I$ denotes the geometrical moment of inertia of the non-cracked cross-section and $l$ the total length of an assumed beam section.

\subsection{Coupling}

Thermo-mechanical coupling is achieved via temperature-dependent stress-strain relations. Starting from initial conditions with a constant temperature state in the solid (e.g. $\vartheta_{0}=20{ }^{\circ} \mathrm{C}$ at $t=t_{0}$ ) the temperature distribution at the end of a time step $t+\Delta t$ follows according to Sect. 2.1. It affects the stress-strain relations in each lamella of the discretised body and thus governs sectional equilibrium (Sect. 2.2). Since material's stiffness and strength decrease progressively with increasing temperature, strains have to increase to ensure equilibrium of forces. If equilibrium cannot be achieved anymore, the structure fails. Figure 4 recapitulates this basic calculation scheme.

To obtain total deflections $\delta$, the corresponding stress $\left(\delta^{\sigma}\right)$ and temperature $\left(\delta^{\text {th }}\right)$ induced portions are additively superimposed. Since distributed cracking is expected for SFRC structures reinforced with additional rebar and 


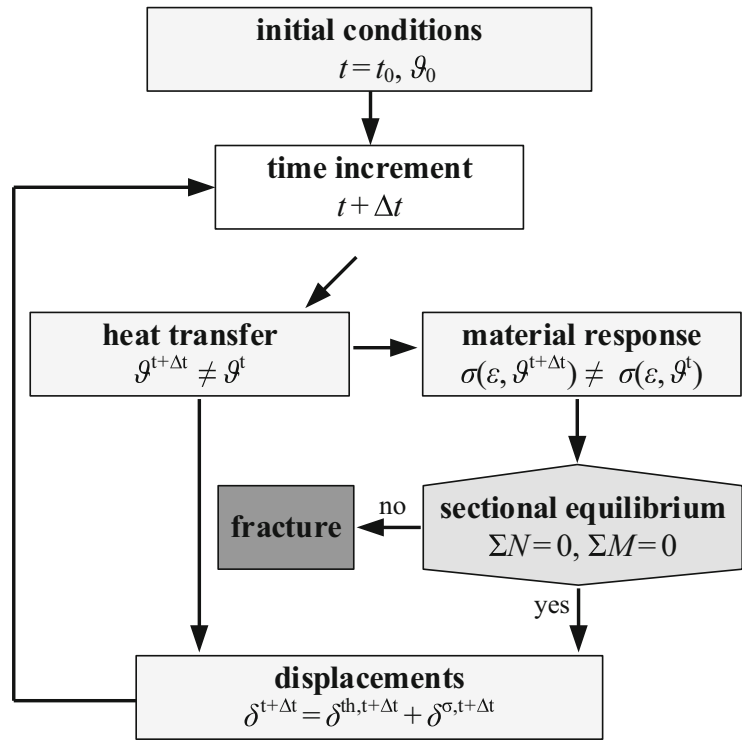

Fig. 4 Flow chart of the calculation scheme of the coupled thermo-mechanical model

Eq. (16) serves to derive $\delta^{\sigma}$, it must be replaced by Eq. (24) in case of single localised cracking.

$\delta^{\text {th }}$ depends on the thermal strains $\varepsilon^{\text {th }}$, which usually turn out highly nonlinear distributed over the height with maxima on the heated face. Since $\varepsilon^{\text {th }}$ equals to the product of temperature difference and thermal expansion coefficient-Eq. (12)-the temperature gradient can be calculated instead to obtain $\delta^{\text {th }}$. For convenience, the temperature field over the cross section's height is partitioned into constant, linear and residual nonlinear parts [36]. Only the linear part-the temperature gradient $\Delta \vartheta$-causes vertical deflections. The others induce axial deformations or constraints. The gradient $\Delta \vartheta$ reads

$\Delta \vartheta=\frac{h}{I} \int_{A} \vartheta(z) z \mathrm{~d} A$

or when discretised with $i=1$ to $m$ lamellae $A_{i}$ over the cross-section's height

$\Delta \vartheta=\frac{h}{I} \sum_{i=1}^{m} \vartheta_{i} z_{i} A_{i}$

Employing the principle of virtual work, thermal deflections are obtained integrating the product of thermal curvatures $\kappa^{\text {th }}=\left(\alpha_{\mathrm{T}} \Delta \vartheta\right) / h$ and a virtual bending moment $\bar{M}(x)$ along the effectively heated length $l_{\mathrm{eff}, h}$ of a specimen [31].

$$
\begin{aligned}
\delta^{\text {th }}(x) & =\int_{0}^{l_{\text {eff, }}} \bar{M}(x) \kappa^{\text {th }}(\vartheta) \mathrm{d} x \\
& =\int_{0}^{l_{\text {eff, }}} \bar{M}(x) \frac{\alpha_{\mathrm{T}}(\vartheta) \Delta \vartheta}{h} \mathrm{~d} x
\end{aligned}
$$

\subsection{Material response and properties at elevated temperatures}

In general, analysis relies on well-established material equations and parameters from literature [7, 21, 22, 28, 37] when available. Table 1 summarises material parameters for PC and rebar and lists general thermal characteristics while reference to relevant literature sources is made. Beyond that, new approaches are proposed to model SFRC's effective conductivity and its softening behaviour as a function of temperature.

\subsubsection{Thermal parameters of SFRC}

The conductivity of SFRC $\lambda_{\text {SFRC }}$ is proposed to be computed from a weighted average of volumes of concrete and steel. Thus, a homogenous composite is assumed which holds true, if the representative length of specimens and discretisation considerably exceeds the internal lengths of fibres and aggregates. Introducing the fibre volume content $V_{\mathrm{f}}$ and the conductivities $\lambda_{\mathrm{c}}$ and $\lambda_{\mathrm{s}}$ of concrete and steel, $\lambda_{\text {SFRC }}$ reads:

$\lambda_{\mathrm{SFRC}}(\vartheta)=V_{\mathrm{f}} \lambda_{\mathrm{s}}(\vartheta)+\left[1-V_{\mathrm{f}}\right] \lambda_{\mathrm{c}}(\vartheta)$.

While literature on the rule of mixture is generally ample (e.g. [8, 38, 39]), an increased fibre volume content $V_{\mathrm{f}}$ in Eq. (30) yields enhanced conductivities and vice versa. By contrast, the fibre's impact on concrete's density, specific heat capacity and heattransfer as well as thermal expansion coefficients, is considered subordinate [40] and thus neglected. Pure concrete characteristics are assumed.

\subsubsection{Stress-strain relations of SFRC}

Temperature-dependent stress-strain relations of concrete in compression [7] are adopted for SFRC, too, since they do not remarkably differ up to the softening branch [10] as it is with normal temperatures [1-3]. By 
Table 1 Basic thermal parameters and corresponding literature sources

\begin{tabular}{|c|c|c|}
\hline Parameter & Denotation & Value/source \\
\hline$a(\vartheta)$ & Diffusivity & $a=\lambda /\left(\rho c_{\mathrm{p}}\right)$ \\
\hline \multirow[t]{3}{*}{$\lambda(\vartheta)$} & Conductivity & \\
\hline & Concrete & Lower limit acc. to EC 2-1-2, 3.3 .3 (2), [7] \\
\hline & Steel & EC 3-1-2, 3.4.1.3 (1), [37] \\
\hline \multirow[t]{3}{*}{$\rho(\vartheta)$} & Density & \\
\hline & Concrete & EC 2-1-2, $3.3 .2(3),[7]$ \\
\hline & Steel & EC 3-1-2, 3.2.2 (1), [37] \\
\hline \multirow[t]{3}{*}{$c_{\mathrm{p}}(\vartheta)$} & Specific heat capacity & \\
\hline & Concrete & EC 2-1-2, 3.3.2 (1), [7] \\
\hline & Steel & EC 3-1-2, 3.4.1.2 (1), [37] \\
\hline$\varepsilon_{\mathrm{m}}$ & Emission coefficient concrete & 0.7 acc. to $[21,22]$ \\
\hline$\varepsilon_{\mathrm{f}}$ & Emission coefficient fumes & $1.0,[21,22]$ \\
\hline$\sigma_{\mathrm{SB}}\left[\mathrm{W} /\left(\mathrm{m}^{2} \mathrm{~K}^{4}\right)\right]$ & Boltzmann constant & $5.67 \times 10^{-8},[21,22]$ \\
\hline \multirow[t]{4}{*}{$\alpha_{\mathrm{K}}\left(\mathrm{W} / \mathrm{m}^{2} \mathrm{~K}\right)$} & Fictive heat-transfer coefficient & {$[28]$} \\
\hline & Non temperature-exposed concrete surface & 4 \\
\hline & $\begin{array}{l}\text { To consider radiative portions at the non } \\
\text { temperature-exposed concrete surface }\end{array}$ & 9 \\
\hline & Temperature-exposed concrete surface & 25 \\
\hline \multirow[t]{3}{*}{$\alpha_{\mathrm{T}}(\vartheta)$} & Thermal expansion coefficient & $\alpha_{\mathrm{T}}=\varepsilon^{\mathrm{th}} / \Delta \vartheta$ \\
\hline & Concrete & Acc. to EC 2-1-2, 3.3.1 (1), [7] \\
\hline & Steel & Acc. to EC 2-1-2, $3.4(1),[7]$ \\
\hline
\end{tabular}

contrast, a more specific behaviour is proposed in tension. The discrete crack-bridging ability of fibres in fire is captured in a smeared way introducing a multilinear stress-strain relation $\sigma_{t}\left(\varepsilon_{t}, \vartheta\right)$. Based on the material response at a reference temperature of $\vartheta=20^{\circ} \mathrm{C}$, softening with increasing temperatures is modelled by a global, multiplicative softening parameter $k_{\mathrm{t}}^{\mathrm{f}}(\vartheta)$. It represents the ratio of concrete's degraded to initial strength and is defined in the range of $0-1$. To assess the temperature-dependent stiffness a temperature-variant Young's modulus of concrete $E_{\mathrm{c}}(\vartheta)$ is adopted [7]. It represents an artificial numerical value to also integrate the effects of high-temperature creeping [36].

$\sigma_{t}\left(\varepsilon_{t}, \vartheta\right)= \begin{cases}E_{\mathrm{c}}(\vartheta) \varepsilon_{t}, & 0 \leq \varepsilon_{t} \leq \frac{f_{\mathrm{t}} k_{\mathrm{t}}^{\mathrm{f}}(\vartheta)}{E_{\mathrm{c}}(\vartheta)} \\ f_{1}^{\mathrm{f}} k_{\mathrm{t}}^{\mathrm{f}}(\vartheta), & \frac{f_{\mathrm{t}} k_{\mathrm{t}}^{\mathrm{f}}(\vartheta)}{E_{\mathrm{c}}(\vartheta)}<\varepsilon_{t} \leq \varepsilon_{1} \\ f_{1}^{\mathrm{f}} k_{\mathrm{t}}^{\mathrm{f}}(\vartheta)+\frac{\varepsilon_{\mathrm{t}}-\varepsilon_{1}}{\varepsilon_{2}-\varepsilon_{1}}\left[f_{2}^{\mathrm{f}}-f_{1}^{\mathrm{f}}\right] k_{\mathrm{t}}^{\mathrm{f}}(\vartheta), & \varepsilon_{1}<\varepsilon_{\mathrm{t}} \leq \varepsilon_{2}\end{cases}$

Linear-elastic behaviour is assumed up to the tensile strength $f_{\mathrm{t}}$. A bilinear function is used to model the fibre's post-cracking bearing capacity employing two residual strength values $f_{1}^{f}$ and $f_{2}^{f}$ at fixed strains $\varepsilon_{1}$ and $\varepsilon_{2}$, respectively. The concept of two strain values with associated strengths is chosen to comply with the established procedure of material classifications via standard bending tests in [1-3]. The strains $\varepsilon_{1}=3.5 \%$ o and $\varepsilon_{2}=25 \%$ correspond to crack widths of $w_{1} \approx 0.45 \mathrm{~mm}$ and $w_{2} \approx 3.15 \mathrm{~mm}$ employing $l_{\mathrm{ch}-}$ $=140 \mathrm{~mm}$ according to [2]. While the strength at $w_{1}$ is associated with the serviceability limit state (SLS), the strength at $w_{2}$ corresponds to ULS conditions $[1,4]$.

The definition of temperature-invariant, constant strain values $\varepsilon_{1}$ and $\varepsilon_{2}$ in Eq. (31) leads to a conservative underestimation since $[7,37]$ report on enlarged strain boundaries for PC and rebar under sustained fire exposure. Figure 5 illustrates the derived stress-strain relations in tension and compression. It should be noted that discontinuity in the plotted temperaturedependent stress-strain curves is virtually due to intended cuts in the strain scales highlighted by dashdotted lines. 
Fig. 5 Temperaturedependent stress-strain relations of SFRC in tension and compression

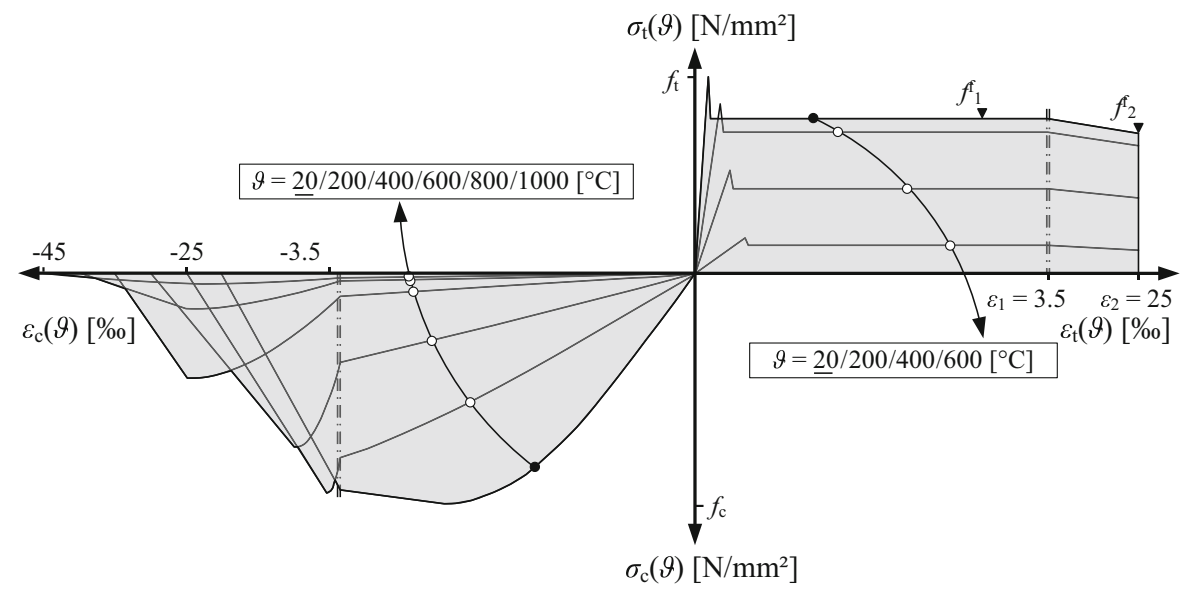

Experimental data from literature $[9,11-16]$ as well as closed formulas already suggested for PC [7] and SFRC [40] give advice to capture the concrete's temperature-dependent strength independent of a material's composition, the crack width and the mechanical loading factor (SLS or ULS). Then, the relative softening parameter $k_{\mathrm{t}}^{\mathrm{f}}(\vartheta)$ relies on temperatures only.

$k_{\mathrm{t}}^{\mathrm{f}}(\vartheta)=\left[\begin{array}{ll}1, & 20 \leq \vartheta \leq 150^{\circ} \mathrm{C} \\ 1-(\vartheta-150) / 550, & 150<\vartheta \leq 700^{\circ} \mathrm{C} \\ 0, & \vartheta>700^{\circ} \mathrm{C}\end{array}\right]$

It is proposed as a conservative, trilinear function according to Eq. (32) evaluating literature data, shown in Fig. 6 (dashed line). Softening starts, when $\vartheta$ approximately exceeds $150{ }^{\circ} \mathrm{C}$ and continues up to $\vartheta=700{ }^{\circ} \mathrm{C}$. Beyond, no bearing capacity is assumed. As intended, Eq. (32) accurately reflects test results by trend but still conservatively [40].

Since test data reported in [41-43] confirms that bond between rebar and concrete is not significantly influenced by steel fibres, neither at normal nor at elevated temperatures, no additional bond conditions are specified for the stress analyses.

\section{Verification to large-scale fire tests}

For verification purposes large-scale fire tests are carried out in cooperation of the Technical University of Kaiserslautern, the Ruhr-University of Bochum

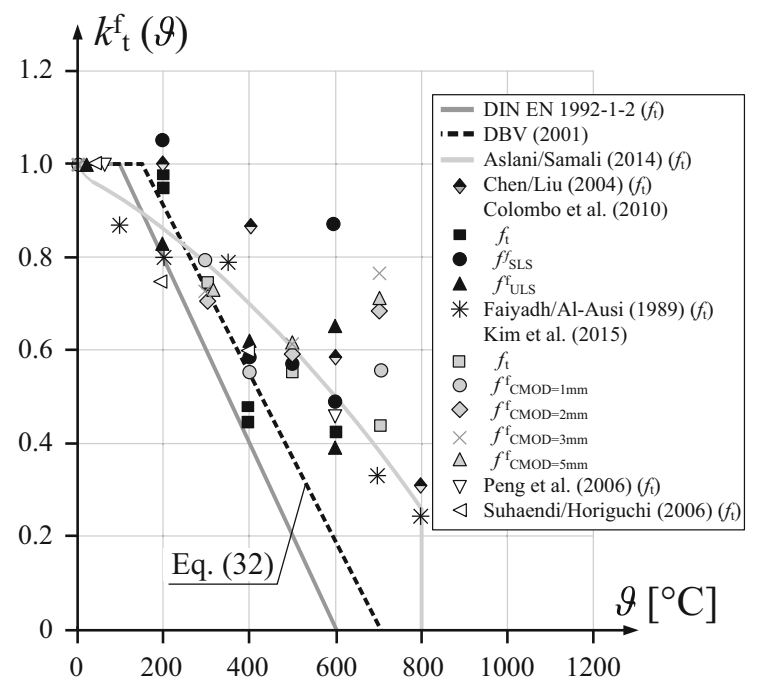

Fig. 6 Experimental data indicates the course of the relative softening parameter $k_{\mathrm{t}}^{\mathrm{f}}$ regarding applied temperatures

(both Germany) and NV Bekaert SA (Belgium). All specimens exhibit the same geometry and concrete strength class $\mathrm{C} 35 / 45$, but are reinforced with different ratios of steel fibres to rebar. The general idea is to vary the ratio in such a way, that reinforcement type changes but bending capacities at ambient temperatures remain almost constant.

\subsection{Experiments}

In total five slabs are exposed to combined thermomechanical actions. Table 2 summarises the amounts of rebar, fibre dosages and fibre types as well as the concrete's and fibre's strengths for all samples. $M_{\mathrm{t} 0}$ denotes the 
Table 2 Material properties and design resistances of the specimens at $\vartheta=20^{\circ} \mathrm{C}$

\begin{tabular}{llllllll}
\hline No. & Rebar & $V_{\mathrm{f}}\left(\mathrm{kg} / \mathrm{m}^{3}\right)$ & Fibre type & $f_{\mathrm{c}} / f_{\mathrm{t}}\left(\mathrm{N} / \mathrm{mm}^{2}\right)$ & $f_{1}^{\mathrm{f}} / f_{2}^{\mathrm{f}}\left(\mathrm{N} / \mathrm{mm}^{2}\right)$ & $M_{\mathrm{t} 0}(\mathrm{kNm})$ & Fibre's bearing contribution $(\%)$ \\
\hline P1 & R335 & - & - & $62.5 / 4.2$ & - & 23.6 & 0 \\
P2 & R188 & 40 & b & $68.5 / 4.2$ & $2.4 / 1.2$ & 30.7 & 54.4 \\
P3 & R188 & 80 & c & $62.5 / 4.1$ & $2.7 / 1.6$ & 37.6 & 62.7 \\
P4 & - & 40 & b & $59.9 / 4.4$ & $1.5 / 0.7$ & 11.1 & 100 \\
P5 & - & 80 & c & $54.8 / 4.3$ & $2.7 / 1.4$ & 20.3 & 100 \\
\hline
\end{tabular}

${ }^{\text {a }}$ Mat providing reinforcement of 3.35 or $1.88 \mathrm{~cm}^{2} / \mathrm{m}$ lengthwise and $20 \%$ of each across

${ }^{\mathrm{b}}$ Dramix 5D 65/60BG, $f_{\mathrm{t}}=2300 \mathrm{~N} / \mathrm{mm}^{2}$

${ }^{\mathrm{c}}$ Dramix 3D 65/60BG, $f_{\mathrm{t}}=1345 \mathrm{~N} / \mathrm{mm}^{2}$

calculated bending capacity for ambient conditions at midspan that nearly coincides for P1, P2 and P5.

To achieve maximum homogeneously dispersed fibres in the concrete, the mix contains a great amount of cement paste and fines. Thereby, the particle-size distribution of the quartzitic aggregates is continuous with a maximum grain diameter of $16 \mathrm{~mm}$. Two types of Dramix steel fibres with one or two-times hooked ends and aspect ratios of 65 are used in dosages of $V_{\mathrm{f}}=0.5$ and $1.0 \mathrm{vol} \%$, respectively. The mean postcracking tensile strengths $f_{1}^{f}$ and $f_{2}^{f}$ of the fibres have been determined before fire testing on small scale reference beams according to [2]. Despite a strong inherent scatter of the post-cracking strength [35], the fibre contents at hand are always subcritical: $f_{\mathrm{t}}>f_{\mathrm{T}}$ $\mathrm{f} \geq f_{2}$. However, the distinct calculative bearing contributions of fibres regarding $M_{\mathrm{t} 0}$ emphasise fibres' governing impact even when combined with considerable amounts of conventional rebar. For experiments, rectangular mats of cold-formed rebar, steel class $\mathrm{N}$ [7], are used.

To ensure moisture contents of practical relevance, i.e. of about $4 \mathrm{vol} \%$ at testing, the specimens are conditioned for at least three months after concreting. For the experiments, an enclosed fire room is created exposing the single-span slabs on the exterior walls of the furnace and providing insulation elsewhere. Two half shells serve as line supports. Thus, the effective length of the specimens follows to $l_{\text {eff }}=400-16=384 \mathrm{~cm}$, whereas only the inner part of $300 \mathrm{~cm}$ is directly exposed to fire, (Fig. 7). Hence, the effectively heated length $l_{\text {eff, } h}$ lies between $l_{\text {eff }}$ and $300 \mathrm{~cm}$. Motivated by thermal images (Fig. 7, right) it is assumed to the balanced average of $l_{\text {eff }, h}=(384+300) / 2=342 \mathrm{~cm}$.
Mechanical loadings are applied by means of steel plates on top of the slabs. They induce a bending moment of about $17 \mathrm{kNm}$ at mid-span. Heating is applied to the bottom-side according to a standardised temperature time curve [19] for $120 \mathrm{~min}$ at maximum with a fume temperature of

$\theta(t)=20+345 \log (8 t+1)\left[{ }^{\circ} \mathrm{C}\right]$ with $t[\min ]$.

As failure criterions, a maximum deflection $\delta_{\max }$ or rather a maximum deflection rate $\dot{\delta}_{\text {max }}$ apply [44] that both depend on the static height $d$ of the slab $(d \approx 15 \mathrm{~cm})$ and its length.

$$
\begin{aligned}
\delta_{\max } & =\frac{l}{400 d}[\mathrm{~mm}] \text { or } \dot{\delta}_{\max }=\frac{\partial \delta_{\max }}{\partial t} \\
& =\frac{l}{900 d}[\mathrm{~mm} / \mathrm{min}]
\end{aligned}
$$

Vertical displacements are continuously recorded at the quarter points of the specimens while temperature data is collected at 25 discrete measurement points uniformly distributed over the slab's volume. Panel thermometers monitor heating of the furnace by gas powered burners.

\subsection{Fire resistances and failures}

The purely fibre reinforced samples collapsed early after 7 (P4) and 41 (P5) minutes of fire exposure. A single and widely opened crack characterised failure and was accompanied by intensive spalling at the bottom face. This can be traced back to two effects: first, a scattering post-cracking tensile strength of SFRC and second, the statically determined single span system that does not allow stresses to redistribute and induces local cracks at the weakest section. By contrast, P1, P2 and P3 
Fig. 7 Test setup in terms of geometry and loadings as well as results of thermal imaging

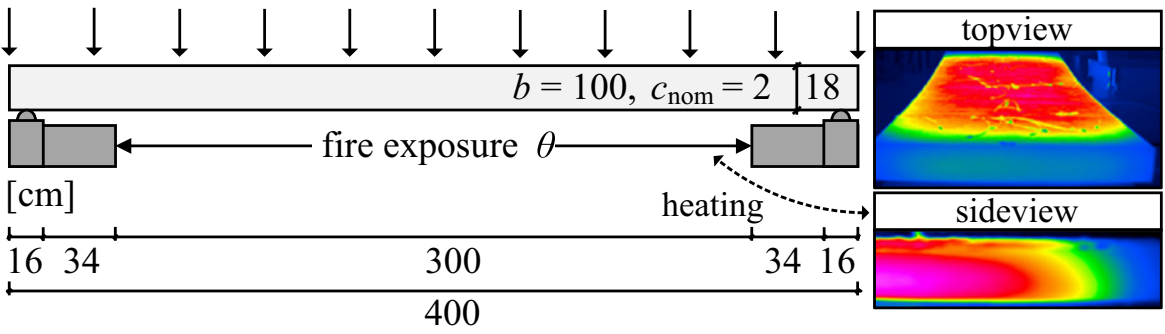

with additional rebar exhibit multiple cracking and large deflections up to $\delta=l / 30$. Intense concrete spalling does not occur. While $\mathrm{P} 1\left(V_{\mathrm{f}}=0\right)$ resisted heating for about $110 \mathrm{~min}, \mathrm{P} 2$ and $\mathrm{P} 3\left(V_{\mathrm{f}}>0\right)$ even outlived $120 \mathrm{~min}$. Moreover, the latter two have shown an increased bending stiffness compared to P1 throughout the experiment, although the values converged with sustained fire exposure.

\subsection{Temperature fields}

For numerical analysis of heat transmission the slabs are discretised in the $x-z$-plane while the transverse direction is neglected. Thus, a constant temperature over the width is supposed as documented by another thermographic image in Fig. 7, right, too. In spreadsheet analysis [23-26], the specimen and its boundaries are idealised by a set of perpendicular cells, similar to Fig. 1. Each cell is attributed either to an element made from concrete, rebar or to environmental conditions, i.e. exposed to fire or to ambient air. Individual element sizes depend on the material and the position within the solid. Here, the slabs are subdivided into 40 elements lengthwise and 25 elements over the height, adaptively reducing their sizes to consider rebar and concrete cover. Reinforcing mats are represented by two layers of elements superimposed upon each other. The lower layer models bars in longitudinal direction, the upper one those across.

Up to $120 \mathrm{~min}$ at maximum, the transient temperature fields are continuously and explicitly updated. Element sizes and assigned thermal parameters limit the size of a time step to $\Delta t=1 \mathrm{~s}$ regarding Eq. (11).

Subsequently, the numerical results-particularly with regard to the smeared parameter of thermal conductivity $\lambda_{\mathrm{SFRC}}$ - are validated by experimental data. On the left, Fig. 8 displays general temperature distributions after 15, 60 and 120 min of heating. For the same points in time, calculated temperature distributions over the section's height (coloured dashed lines) are contrasted to experimental ones on the right. By trend all dots fall on a straight line (perfect match) whereas different fibre volume contents of $V_{\mathrm{f}}=0,0.5$ and $1 \%$ can be distinguished. In detail, temperatures are assessed at the top and bottom side as well as at five additional points across the thickness. As the inner sensors could not be fixed directly to the formwork, they are more sensitive to slipping during concreting. Deviations from the sensors' reference positions might have caused some scatter in the results. As expected, numerical and experimental results document clearly nonlinear temperature gradients over the height. Generally, the temperature increase lasts on the longer the fire burns, whereas the trend mitigates with less distance to the fire-exposed side. While maximum temperatures occur at the fire facing side, minimum values are found on the opposite face.

Theoretically, increasing the fibre volume contents goes along with enhanced body temperatures due to accelerated heat flux. The dashed lines in Fig. 8, right reveal this aspect by certain offsets that rise with time. However and despite the scatter inherent to measured temperatures, no significant influence of the fibre amount $\left(V_{\mathrm{f}} \leq 1.0 \mathrm{vol} \%\right.$ ) on the concrete's heating rate becomes obvious during the experiments. Moreover, recalculations employing unmodified thermal parameters of concrete with respect to [7] $\left(\lambda_{\mathrm{SFRC}}=\lambda_{\mathrm{c}}\right.$ according to [40]) match to the test data best. Assuming $V_{\mathrm{f}}$ in correspondence to its real physical values even slightly reduces the accuracy of recalculations.

\subsection{Transient bearing capacities}

Based on the transient temperature fields, temperatureand stress-dependent deflections are obtained. Since 


\section{$t$ [min] numerical results}
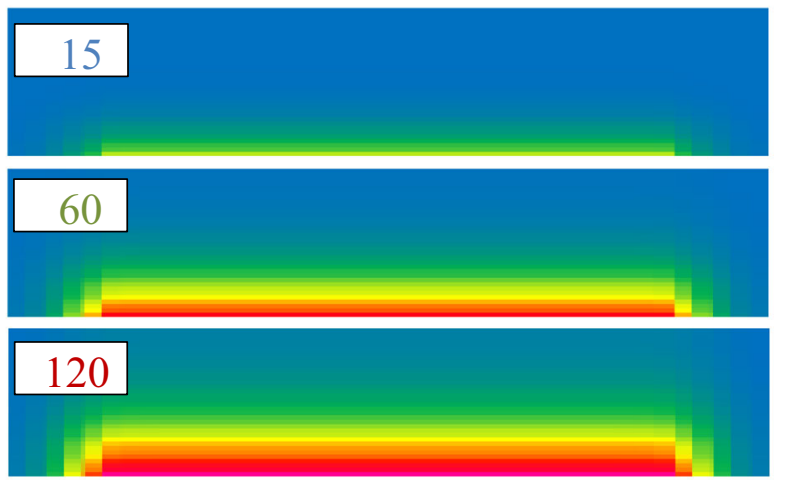

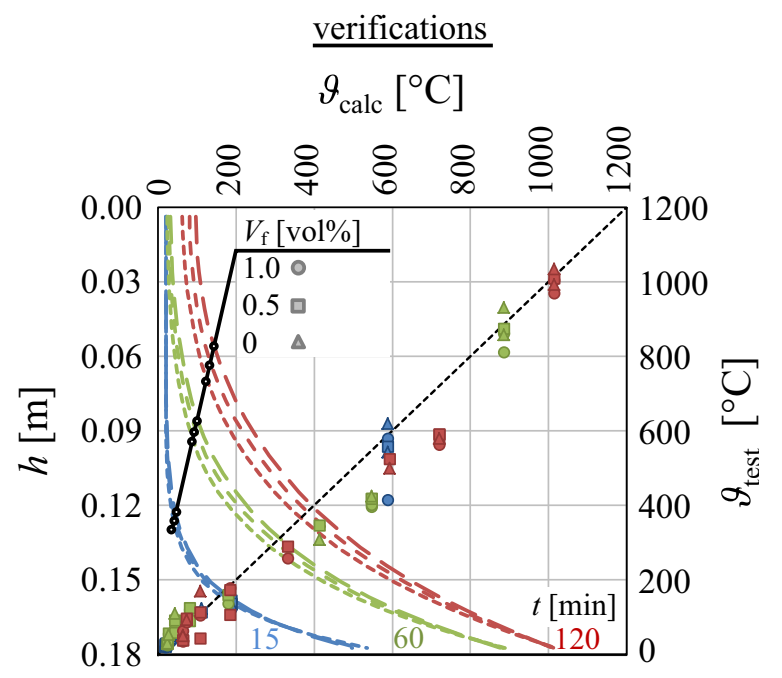

Fig. 8 Measured vs. computed temperature distributions after $t=15,60$ and $120 \mathrm{~min}$ of fire exposure

specimens $\mathrm{P} 1$ to $\mathrm{P} 3$ are reinforced, multiple cracking is expected and recalculation employs the procedure in Sect. 2.2.1. By contrast P4 and P5 are purely fibre reinforced and thus the plastic hinge model (Sect. 2.2.2) is used. The slabs with rebar are discretised with 20 elements along the longitudinal axis to cover the different softening states from variable bending. Mean material properties are assumed as listed in Table 2 or supplemented according to standard code provisions of [45].

\subsubsection{Cross-sectional level}

To capture the total impact of heating on the bearing behaviour, the cross-sectional response is analysed first. For sections with rebar (P1 to P3) exposed to fire for $120 \mathrm{~min}$ and a maximum surface temperature of $1000{ }^{\circ} \mathrm{C}$ moment-curvature relations are derived. In Fig. 9 they are contrasted to the ones obtained initially for a uniform temperature of $\theta=20^{\circ} \mathrm{C}$. As expected, maximum bending capacities decrease for all three fibre contents (P1, P2, P3) with increased temperatures. However, this is still true after heating. Similar to additional bearing capacities provided by rebar, fibres contribute to the overall resistance even when exposed to fire. Although strength and stiffness are on a significant lower level then. Most surprising fibres remain beneficial even if-from the model's point of view-almost all performance within the concrete cover at temperatures higher than $700{ }^{\circ} \mathrm{C}$ is lost.

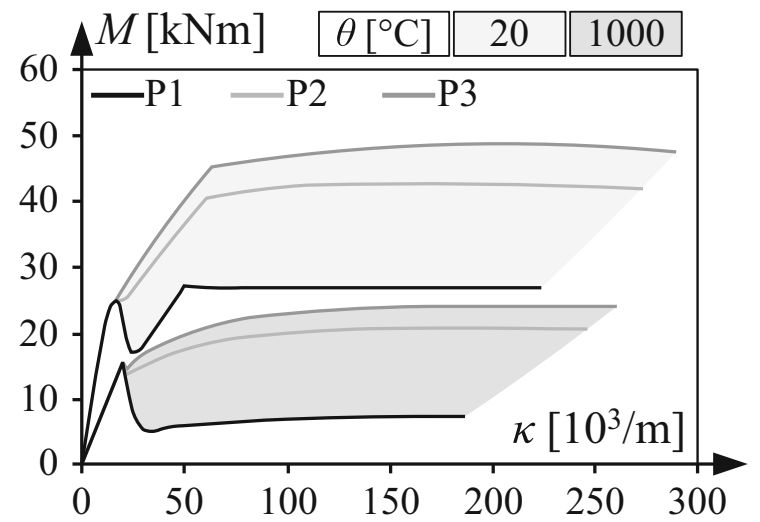

Fig. 9 Temperature-dependent moment-curvature relations of specimens $\mathrm{P} 1, \mathrm{P} 2$ and $\mathrm{P} 3$

\subsubsection{Structural level}

All five slab tests are finally recalculated and compared to the experimental results. To achieve transient evaluations, the mid-span deflections $\delta$ are contrasted over a continuously increasing fume temperature $\theta$ in Fig. 10. Numerical and experimental curves correspond well, no matter if distributed cracking (P1 to P3) or localised failures (P4, P5) are considered. However, in the latter case, failure actually occurs earlier and calculations tend to underestimate the true brittleness. Furthermore, it should be noted that the deflections strongly increase if temperature exceeds $600{ }^{\circ} \mathrm{C}$. 
Fig. 10 Measured versus calculated temperaturedependent deflections at mid-span
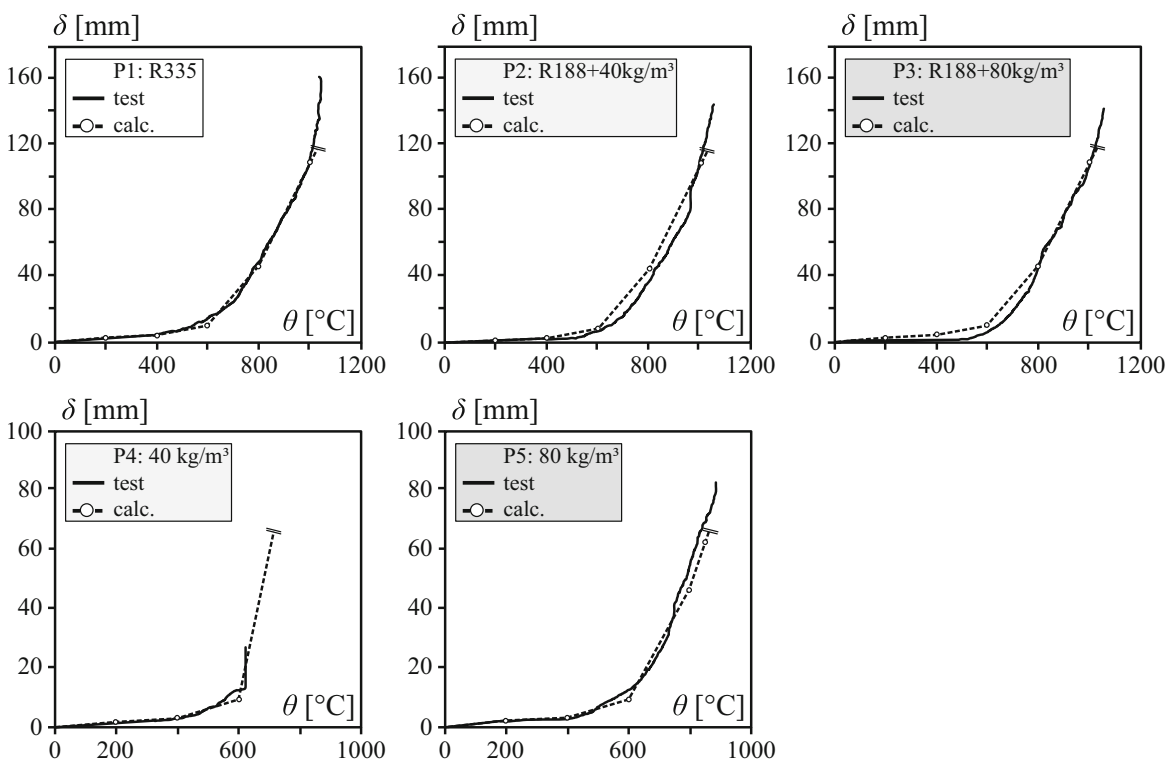

While temperature effects dominate at that point, stress induced portions become important.

\section{Conclusions}

Within this contribution, a thermo-mechanical model is proposed to investigate transient bearing capacities of SFRC slabs with and without additional rebar exposed to elevated temperatures. The temperaturedependent tensile strength of the SFRC is derived based on test results from the literature. The accuracy of the coupled model is validated using results obtained from large-scale fire tests performed on reinforced concrete slabs. Both tests and numerical data are, on average, in good agreement. Based on the presented research, the following conclusions can be drawn:

- Concrete's heating rate is not significantly enhanced by steel fibres in dosages up to about $1.0 \%$ in volume. The thermal parameters describing heat capacity, density and conductivity as well as the thermal expansion coefficient of PC can be adopted for SFRC as a first order estimate.

- The temperature-dependent but strain-independent softening of fibre's post-cracking tensile strength can be reliably predicted by means of a bilinear function, as originally proposed in [40]. This function assumes undisturbed conditions until the solid temperature reaches $150{ }^{\circ} \mathrm{C}$ and assumes a full loss of bearing capacity at $700{ }^{\circ} \mathrm{C}$.

- SFRC without rebar might extensively spall when subjected to fire. Brittle failure was observed in the single-span systems very early after fire exposure, i.e. after 7 and $41 \mathrm{~min}$, due to single cracking. In both cases, the radiation temperature of the fumes did not exceed approximately $600{ }^{\circ} \mathrm{C}$.

- SFRC containing additional rebar exhibits multiple cracking, pronounced deflections and reduced spalling. The ratio of specimen's length to its maximum vertical deflection reaches about $\delta=l /$ 30. Thus, a ductile material behaviour prevails up to about $1000{ }^{\circ} \mathrm{C}$ of outer exposure.

- The combination of mechanically anchored steel fibres and rebar results in enhanced fire resistance durations and higher bending stiffness compared to reinforced concrete. However, the necessary residual strength values corresponding to fire resistance durations of 90 min (R90) could be met in both cases.

Acknowledgements The financial support provided by NV Bekaert SA for the presented experiments is gratefully acknowledged. Additionally, the authors would like to thank Prof. Catherina Thiele as well as Daniele Casucci, M.Sc. from TU Kaiserslautern, Germany for careful execution of all tests. The authors very much appreciate the support of Dr. M. A. Ahrens in elaborating the paper. 


\section{Compliance with ethical standards}

Conflict of interest The authors declare that they have no conflict of interest.

Open Access This article is distributed under the terms of the Creative Commons Attribution 4.0 International License (http:// creativecommons.org/licenses/by/4.0/), which permits use, duplication, adaptation, distribution and reproduction in any medium or format, as long as you give appropriate credit to the original author(s) and the source, provide a link to the Creative Commons license and indicate if changes were made.

\section{References}

1. RILEM TC 162-TDF (2003) Test and design methods for steel fibre reinforced concrete-background and experiences. In: Schnütgen B, Vandevalle L (eds) Proceedings of 31 RILEM TC-162-TDF workshop, Bochum, Germany

2. DAfStb (German Committee for Structural Concrete) (2015) DAfStb H614-2015 commentary on the DAfStb guideline "steel fibre reinforced concrete", Berlin

3. Model Code 2010 (2013) fib model code 2010. Fédération Internationale du Béton

4. Gödde L, Strack M, Mark P (2010) Bauteile aus Stahlfaserbeton und stahlfaserverstärktem StahlbetonHilfsmittel für Bemessung und Verformungsabschätzung nach DAfStb-Richtlinie Stahlfaserbeton. Beton- und Stahlbetonbau 105(2):78-91

5. Heek P, Mark P (2016) Load-bearing capacities of SFRC elements accounting for tension stiffening with modified moment-curvature relations. In: ACI-SP 310 + fib bulletin no. 79: fibre reinforced concrete-from design to structural applications, pp 301-310

6. Dehn F, Herrmann A (2014) Steel fibre-reinforced concrete (SFRC) in fire-normative and pre-normative requirements and code-type regulations. In: Proceedings of 1 st joint ACIfib international work. Fibre reinforced concrete-from design to structural applications, Canada, pp 2-8

7. DIN EN 1992-1-2 (2010) Design of concrete structurespart 1-2: general rules-structural fire design, Berlin

8. Khaliq W, Kodur V (2011) Thermal and mechanical properties of fibre reinforced high performance self-consolidating concrete at elevated temperatures. Cem Concr Res 41:1112-1122

9. Aslani F, Samali B (2014) Constitutive relationship for steel fibre reinforced concrete at elevated temperatures. Fire Technol 50:1249-1268

10. Chen GM, He YH, Yang H, Chen JF, Guo YC (2014) Compressive behaviour of steel fibre reinforced recycled aggregate concrete after exposure to elevated temperatures. Constr Build Mater 71:1-15

11. Chen B, Liu J (2004) Residual strength of hybrid-fibre-reinforced high-strength concrete after exposure to high temperatures. Cem Concr Res 34(6):1065-1069

12. Colombo M, di Prisco M, Felicetti R (2010) Mechanical properties of steel fibre reinforced concrete exposed at high temperatures. Mater Struct 43:475-491
13. Faiyadh FI, Al-Ausi MA (1989) Effect of elevated temperature in splitting tensile strength of fibre concrete. Int $\mathbf{J}$ Cem Compos Lightweight Concr 11(3):175-178

14. Kim J, Lee G-P, Moon DY (2015) Evaluation of mechanical properties of steel-fibre-reinforced concrete exposed to high temperatures by double-punch test. Constr Build Mater 79:182-191

15. Peng GF, Yang WW, Zhao J, Liu YF, Bian SH, Zhao LH (2006) Explosive spalling and residual mechanical properties of fibre-toughened high-performance concrete subjected to high temperatures. Cem Concr Res 36:723-727

16. Suhaendi SL, Horiguchi T (2006) Effect of short fibres on residual permeability and mechanical properties of hybrid fibre reinforced high strength concrete after heat exposure. Cem Concr Res 36:1672-1678

17. Diederichs U (1999) Hochtemperatur- und Brandverhalten von hochfestem Stahlfaserbeton. In: Teutsch M (ed) Betonbau - Forschung, Entwicklung und Anwendung, vol 142. Schriftenreihe des Instituts für Baustoffe, Massivbau und Brandschutz, Braunschweig, pp 67-76

18. Hertel C, Orgass M, Dehn F (2002) Brandverhalten von faserfreiem und faserverstärktem Beton. In: König G, Holschemacher K, Dehn F (eds) Faserbeton - Innovationen im Bauwesen. Bauwerk Verlag, pp 63-76

19. DIN EN 1991-1-2 (2010) Actions on structures-part 1-2: general actions-actions in structures exposed to fire, Berlin

20. Carslaw HS, Jaeger JC (1959) Conduction of heat in solids, 2nd edn. Oxford University Press, Oxford

21. Mannsfeld T (2011) Tragverhalten von Stahlbetonflächentragwerken unter Berücksichtigung der temperaturbedingten Nichtlinearitäten im Brandfall. Dissertation, TU Wuppertal

22. Lichte U (2004) Klimatische Temperatureinwirkungen und Kombinationsregeln bei Brückenbauwerken. Ph.D. thesis, München, Germany

23. Sanio D, Mark P, Ahrens MA (2017) Temperaturfeldberechnung für Brücken: Umsetzung mit Tabellenkalkulationen. Beton- und Stahlbetonbau 112(2):85-95

24. Mark P (2003) Optimierungsmethoden zur Biegebemessung von Stahlbetonquerschnitten. Beton- und Stahlbetonbau 98(9):511-519

25. Mark P, Strack M (2004) Bending design of arbitrarily shaped steel fibre reinforced concrete sections using optimization methods. In: di Prisco $\mathrm{M}$ et al. (eds) 6th RILEM symposium fibre reinforced concrete (BEFIB 2004), Italy, pp 965-974

26. Mark P (2004) Fundamentgestaltung und Sohlspannungsberechnung mit Optimierungsmethoden und Tabellenkalkulation. Bautechnik 81(1):38-43

27. Tkocz J, Heek P, Mark P (2015) SFRC slabs exposed to fire-experiments, temperature flow and design. ALITinform $6(41): 36-53$

28. Hosser D (2013) Leitfaden Ingenieurmethoden des Brandschutzes. vfdb TB 04-01/3

29. Fouad N (1998) Numerical simulation of the environmental thermal loading of structures. Fraunhofer-IRB, Munich

30. Bhatti A (2002) Practical optimization methods. Springer, New York 
31. König G, Tue NV (2003) Grundlagen des Stahlbetonbaus Einführung in die Bemessung nach DIN 1045-1. TeubnerVerlag, Leipzig

32. Hillerborg A (1980) Analysis of fracture by means of the fictitious crack model, particularly for fibre reinforced concrete. Int J Cem Compos 2(4):177-184

33. Strack M (2008) Modelling of the crack opening controlled load bearing behaviour of steel fibre reinforced concrete under tension and bending. In: Gettu R (eds) Proceedings of 7th RILEM international symposium fibre reinforced concrete — design and applications, BEFIB, India, pp 323-332

34. Bazant ZP, Oh BH (1983) Crack band theory for fracture of concrete. Mater Struct 16(93):155-197

35. Heek P, Ahrens MA, Mark P (2017) Incremental-iterative model for time-variant analysis of SFRC subjected to flexural fatigue. Mater Struct 50(1):62. https://doi.org/10.1617/ s11527-016-0928-Z

36. Heek P, Tkocz J, Thiele C, Vitt G, Mark P (2015) Fasern unter Feuer - Bemessungshilfen für stahlfaserverstärkte Stahlbetondeckenplatten im Brandfall. Beton- und Stahlbetonbau 110(10):656-671

37. DIN EN 1993-1-2 (2010) Design of steel structures-part 1-2: general rules - structural fire design, Berlin
38. Cook DJ, Uher C (1974) The thermal conductivity of fibrereinforced concrete. Cem Concr Res 4:497-509

39. Nagy B, Nehme SG, Szagri D (2015) Thermal properties and modeling of fiber reinforced concretes. Energy Procedia 78:2742-2747

40. DBV (Deutscher Beton- und Bautechnik Verein e.V.) (2001) DBV-2001: Merkblatt Stahlfaserbeton

41. Balazs G, Lubloy E (2012) Reinforced concrete structures in and after fire. Concr Struct 13:72-80

42. Holschemacher K, Weiße D (2004) Bond of reinforcement in fibre reinforced concrete. In: Proceedings of 6th RILEM symposium on fibre reinforced concrete, BEFIB, Italy, pp 349-358

43. Gödde L, Mark P (2015) Numerical simulation of the structural behaviour of SFRC slabs with or without rebar and prestressing. Mater Struct 48(6):1689-1701

44. DIN EN 1365-2 (2012) Fire resistance tests for loadbearing elements-part 2: floors and roofs, Berlin

45. DIN EN 1992-1-1 (2011) Design of concrete structurespart 1-1: general rules and rules for buildings, Berlin 